\title{
Control of Wind Energy Conversion Systems Based on the Modular Multilevel Matrix Converter
}

Article in IEEE Transactions on Industrial Electronics · July 2017

DOI: $10.1109 /$ IIE.2017.2733467

CITATIONS

5

7 authors, including:

Matias Diaz

University of Santiago, Chile

30 PUBLICATIONS $\mathbf{8 4}$ CITATIONS

SEE PROFILE

Mauricio Espinoza

University of Costa Rica

20 PUBLICATIONS 49 CITATIONS

SEE PROFILE
READS

545

Some of the authors of this publication are also working on these related projects:

Roberto Cardenas

University of Chile

134 PUBLICATIONS 4,021 CITATIONS

SEE PROFILE

Andrés Mora

Universidad Técnica Federico Santa María

19 PUBLICATIONS 79 CITATIONS

SEE PROFILE

Project New AC/AC Converter Topologies View project

Control Systems and Hardware Topologies for Modular Multilevel Converter Applications View project 


\title{
Control of Wind Energy Conversion Systems Based on the Modular Multilevel Matrix Converter
}

\author{
Matias Diaz, Student Member, IEEE, Roberto Cardenas, Senior Member, IEEE, Mauricio \\ Espinoza, Student Member, IEEE, Felix Rojas, Andres Mora, Member, IEEE, Jon C. Clare, \\ Senior Member, IEEE, and Pat Wheeler, Senior Member, IEEE
}

\begin{abstract}
The nominal power of single Wind Energy Conversion Systems (WECS) has been steadily growing, reaching power ratings close to $10 \mathrm{MW}$. In the power conversion stage, medium-voltage power converters are replacing the conventional low-voltage back-to-back topology. Modular Multilevel Converters have appeared as a promising solution for Multi-MW WECSs, due to their modularity, and the capability to reach high nominal voltages. This paper discusses the application of the Modular Multilevel Matrix Converter $\left(\mathrm{M}^{3} \mathrm{C}\right)$ to drive MultiMW WECSs. The modelling and control systems required for this application are extensively analysed and discussed in this paper. The proposed control strategies enable decoupled operation of the converter, providing maximum power point tracking (MPPT) capability at the generator-side, grid code compliance at the grid-side [including Low Voltage Ride Through Control (LVRT)], and good steady state and dynamic performance for balancing the capacitor voltages in all the clusters. Finally, the effectiveness of the proposed control strategy is validated through simulations and experimental results conducted with a 27 power-cell prototype.
\end{abstract}

Index Terms-Modular Multilevel Converters, Wind Energy Conversion Systems, Low Voltage Ride Through.

\section{INTRODUCTION}

$\mathrm{W}$ IND energy has grown more and at a faster rate than all other renewable energy sources. The wind power

Manuscript received December 16, 2016; revised February 24, 2017; accepted July 03, 2017. This work was supported in part by FONDECYT under Grant 1140337, AC3E Basal Project grant Nr. FB0008 and CONICYT Doctorado Nacional grant Nr. 2013-21130721.

M. Diaz and F. Rojas are with the Electrical Engineering Department, University of Santiago of Chile, Santiago 9170124, Chile (e-mail: matias.diazd@usach.cl; felix.rojas@usach.cl).

R. Cardenas is with the Electrical Engineering Department, University of Chile, Santiago 8370451, Chile (e-mail: rcd@ieee.org).

M. Espinoza is with the Electrical Engineering Department, University of Costa Rica, San Jose 11501-2060 UCR, Costa Rica (email: mespinoza@eie.ucr.ac.cr).

A. Mora is with the Electrical Engineering Department, Tech. Univ. Fed. Santa Maria, Valparaiso 110-V, Chile (e-mail: amora@usm.cl).

J. C. Clare and P. Wheeler are with the Department of Electrical and Electronic Engineering, University of Nottingham, Nottingham NG7 2RD, U.K. (e-mail: jon.clare@nottingham.ac.uk; pat.wheeler@nottingham.ac.uk).

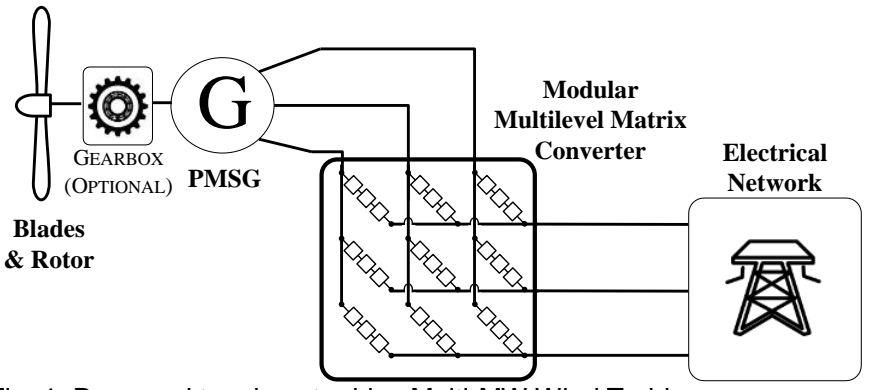

Fig. 1: Proposed topology to drive Multi-MW Wind Turbines

production capacity for the whole world increased from 17.4 GW in 2000 to $432.4 \mathrm{GW}$ in 2015 , positioning wind power as a significant and crucial energy source in areas such as Europe, China and the USA [1]. A continual increase in wind power capacity is expected in the immediate future. The European Wind Energy Association (EWEA) has stated that "wind power would be capable of contributing up to $20 \%$ of EU electricity by $2020,30 \%$ by 2030 and $50 \%$ by 2050 " [2].

A significant part of the required future wind power capacity will be installed offshore, due to the presence of higher wind energy and lower environmental impacts. For offshore applications, upscaling wind turbine dimensions, wind park capacities, and electrical infrastructure have become the focus of recent research. A high power wind turbine can reduce the cost structure of offshore WECS [2]. For this reason, wind turbine nominal powers and rotor diameters have increased to $8 \mathrm{MW}-140 \mathrm{~m}$ in 2015. In addition, two 10MW WECSs, the Seatitan from WindTec and the Sway 10MW, are expected to be introduced to the market shortly [3], [4].

When the penetration of Wind Energy is high, sudden disconnections of large wind power plants may have a significant influence on the stability of power systems. Therefore, stringent grid codes have been enforced recently, which encompass active power control to support the grid frequency, reactive power control to support the grid voltage, power quality, power controllability, and Fault Ride Through (FRT) capability. FRT requirements regulate the behavior under Low-Voltage Ride-Through, and High-Voltage Ride Through (HVRT) grid voltage conditions and probably represent the primary concern for wind turbine and power converter manufacturers since grid voltage sag-swell are the most common disturbances present in electrical power systems [5]. Despite the trend for Multi-MW Wind Turbines, most of 
the installed WECSs are based on low-voltage power converters, usually equipped with $1700 \mathrm{~V}$ IGBT devices for connection to $690 \mathrm{~V}$. Therefore, high currents are required at the output of Multi-MW WECS. Thus, medium voltage converter with flexible control strategies could be better suited for this task [3], [6].

In this context, this paper presents a novel application of the $\mathrm{M}^{3} \mathrm{C}$ to control a high-power WECS, as shown in Fig. 1. The $\mathrm{M}^{3} \mathrm{C}$ is a modular AC-AC converter able to reach high-voltage levels, by the series connection of full-bridge modules. This converter has some advantages compared to conventional twolevel topologies for high-power applications, for instance, full modularity, simplicity to reach high voltage levels, control flexibility, power quality and redundancy [7]. In offshore applications, reliability is one of the key parameters. Therefore, the possible redundancy of the $\mathrm{M}^{3} \mathrm{C}$, achieved by adding redundant modules [8], is a major advantage of this topology. The application of $\mathrm{M}^{3} \mathrm{Cs}$ topologies to WECSs could lead to reductions in the size of the transformer or even transformerless operation, with the consequent power density increment and weight reduction [9]. In [8], the $\mathrm{M}^{3} \mathrm{C}$ is advantageously compared with others high power converter topologies for wind energy applications.

A topology similar to that shown in Fig. 1 was proposed for WECSs in [10], [11]. However, in these papers, the use of cluster inductors is not considered. Therefore, it is assumed that the only five clusters can switch simultaneously to avoid short circuiting the grid-side/machine-side voltage sources (see [10]). Additionally, a Space Vector Modulation (SVM) algorithm is proposed in [10], [11] to synthesise the cluster voltages. Nevertheless, in an $\mathrm{M}^{3} \mathrm{C}$ composed of $n$ cells there are $3^{9 n}$ possible switching states, therefore the modulation algorithm discussed in [10], [11], is not feasible when more than two cells per cluster are considered. Furthermore, neither variable speed operation nor grid-connected operation of the $\mathrm{M}^{3} \mathrm{C}$ are considered in the aforementioned papers.

The contributions of this paper can be summarised as follows:

- To the best of our knowledge, this is the first paper where LVRT control systems for $\mathrm{M}^{3} \mathrm{C}$ applications (see Fig. 1) are discussed, and experimental results presented.

- A decoupled input/output control for an $\mathrm{M}^{3} \mathrm{C}$ based WECS is proposed and thoroughly analysed in this paper. Similar to the operation of Back-to-Back converters for WECS applications [4], where the presence of a DC-link allows decoupled control of the AC-DC-AC conversion stages, the proposed control strategy enables the decoupled operation of the grid-side and generator-side control systems.

- The regulation of the capacitor voltages is realised using nested control loops, with the outer loops regulating the capacitor voltages (using PI controllers) and the inner control loops regulating the circulating currents. Therefore, the outer control loops regulate the dc-component of the capacitor voltage imbalances with zero steady-state error.

- Finally, experimental validation of the proposed control schemes is provided, including variable speed operation, grid code compliance, and capacitor voltage regulation.

The rest of this paper is organised as follows. In Section II, the $\mathrm{M}^{3} \mathrm{C}$ is discussed. The proposed control systems are

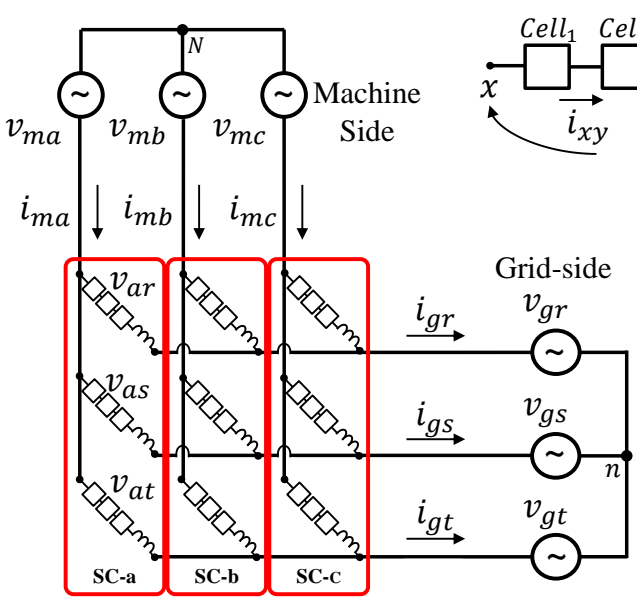

(a)

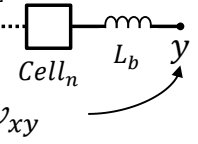

(b)

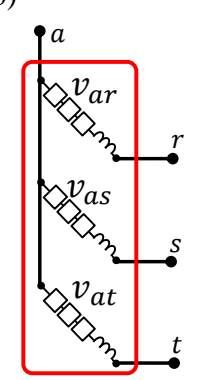

(c)
Fig. 2: Modular Multilevel Matrix Converter Topology. (a) Whole converter. (b) $\mathrm{M}^{3} \mathrm{C}$ Cluster composition. (c) $\mathrm{M}^{3} \mathrm{C}$ Sub-Converter.

presented in Section III. Then, simulation and experimental results are analysed and extensively discussed in Section IV and Section V, respectively. Finally, an appraisal of the proposed control methodology is presented at the Conclusions.

\section{Modular MultileVel Matrix Converter}

Fig. 2(a) shows the converter topology used in this work. The $\mathrm{M}^{3} \mathrm{C}$ has nine clusters connecting the phases of the input or generator $[a, b, c$ in Fig. 2(a)], to the three phases of the output or grid $[r, s, t$ in Fig. 2(a)]. Each of the nine clusters shown in Fig. 2(a) is composed of $n$ Full H-Bridge cells and one inductor (see Fig. 2(b)). As shown in Fig. 2(c), each phase of the generator is connected to the phases $(r, s, t)$ using a Sub-Converter (SC).

The switching frequency and voltage levels of a cluster depend on the modulation technique and the number of seriesconnected cells, leading to a low harmonic distortion when a high number of cells are considered. It is important to note that for this topology, the capacitor voltages of each cell are floating and, therefore, they could charge-discharge during the operation of the converter, particularly when variable speed operation of the generator is considered. Therefore, the capacitor voltages have to be controlled to achieve low voltage ripple around a steady state operating point.

Recently, a decoupled modelling approach for the $\mathrm{M}^{3} \mathrm{C}$ has been reported in [12], [13]. In these papers, the basic approach is to use a two-stage- $\alpha \beta 0$ transformation which is briefly discussed below. Applying Kirchhoff's circuit laws to Fig. 2(a), and assuming that the grid and the generator are ideal voltage sources, the expression of (1) is obtained.

$\left[\begin{array}{lll}v_{m a} & v_{m b} & v_{m c} \\ v_{m a} & v_{m b} & v_{m c} \\ v_{m a} & v_{m b} & v_{m c}\end{array}\right]=L_{b} \frac{d}{d t}\left[\begin{array}{lll}i_{a r} & i_{b r} & i_{c r} \\ i_{a s} & i_{b s} & i_{c s} \\ i_{a t} & i_{b t} & i_{c t}\end{array}\right]+\left[\begin{array}{lll}v_{a r} & v_{b r} & v_{c r} \\ v_{a s} & v_{b s} & v_{c s} \\ v_{a t} & v_{b t} & v_{c t}\end{array}\right]+$
$\left[\begin{array}{lll}v_{g r} & v_{g r} & v_{g r} \\ v_{g s} & v_{g s} & v_{g s} \\ v_{g t} & v_{g t} & v_{g t}\end{array}\right]+v_{N n}\left[\begin{array}{ccc}1 & 1 & 1 \\ 1 & 1 & 1 \\ 1 & 1 & 1\end{array}\right]$

The subscript " $g$ " represents grid-side variables and the subscript " $m$ " represents the machine(generator)-side variables. Notice that in (1) the nine cluster voltages $v_{a r} \cdots v_{c t}$ are synthesised by the converter using the modulation indexes obtained from the control systems 


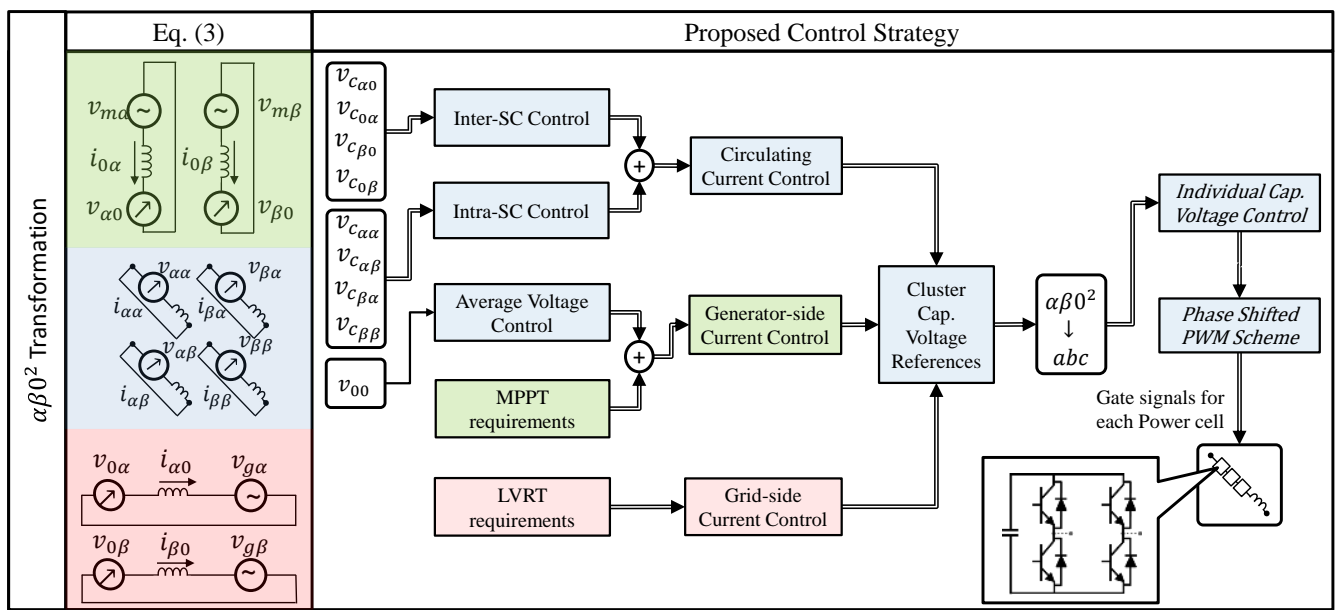

Fig. 3: Overview of the proposed control strategy.

discussed in this paper. Modulation indexes for each cell are normalised to consider the dc-link voltage variation of each cell capacitor (see Section III.D).

The $\alpha \beta 0$ transformation matrix, i.e., $C_{\alpha \beta 0}$ is defined as:

$$
C_{\alpha \beta 0}=\sqrt{\frac{2}{3}}\left[\begin{array}{ccc}
1 & -1 / 2 & -1 / 2 \\
0 & \sqrt{3} / 2 & -\sqrt{3} / 2 \\
1 / \sqrt{2} & 1 / \sqrt{2} & 1 / \sqrt{2}
\end{array}\right]
$$

The two-stage- $\alpha \beta 0$ transformation of the $a b c$ signals is realised by the pre-multiplication of (1) by the $C_{\alpha \beta 0}$ matrix and post-multiplication by $\mathrm{C}_{\alpha \beta 0}^{\mathrm{t}}$. After some manipulations (3) is obtained:

$\sqrt{3}\left[\begin{array}{ccc}0 & 0 & 0 \\ 0 & 0 & 0 \\ v_{m \alpha} & v_{m \beta} & 0\end{array}\right]=L_{b} \frac{d}{d t}\left[\begin{array}{ccc}i_{\alpha \alpha} & i_{\beta \alpha} & i_{\mathrm{o} \alpha} \\ i_{\alpha \beta} & i_{\beta \beta} & i_{\mathrm{o} \beta} \\ i_{\alpha 0} & i_{\beta 0} & i_{00}\end{array}\right]+\left[\begin{array}{ccc}v_{\alpha \alpha} & v_{\beta 0} & v_{0 \alpha} \\ v_{\alpha \beta} & v_{\beta \beta} & v_{0 \beta} \\ v_{\alpha 0} & v_{\beta 0} & v_{00}\end{array}\right]+$

$\sqrt{3}\left[\begin{array}{ccc}0 & 0 & v_{g \alpha} \\ 0 & 0 & v_{g \beta} \\ 0 & 0 & 0\end{array}\right]+\left[\begin{array}{ccc}0 & 0 & 0 \\ 0 & 0 & 0 \\ 0 & 0 & 3 v_{N n}\end{array}\right]$

where the currents $i_{\alpha 0}+j i_{\beta o}=\left(i_{m \alpha}+j i_{m \beta}\right) / \sqrt{3}$ and the currents $i_{o \alpha}+j i_{o \beta}=\left(i_{g \alpha}+j i_{g \beta}\right) / \sqrt{3}$. The variables $\left(i_{m \alpha}\right.$, $\left.i_{m \beta}\right)$ are dependent on the generator side currents, meanwhile $\left(i_{\mathrm{g} \alpha}, i_{\mathrm{g} \beta}\right)$ are dependent on the grid side currents. The currents $i_{\alpha \alpha}, i_{\beta \alpha}, i_{\alpha \beta}$ and $i_{\beta \beta}$ are not present either at the generator side nor at the grid side and are called "circulating currents".

\section{Control Strategy fOR THE M3C based WECSS}

The proposed control strategy provides decoupled regulation of the converter, the input (generator-side), and the output (grid-side). For balanced operation, the average value of each capacitor voltage has to be regulated to an identical reference value. The voltage differences (imbalances) are compensated using circulating currents. As discussed in this section, for the application proposed in this paper four circulating currents are required. These current components are referred to the coordinates of the two-stage- $\alpha \beta 0$ transformation [see (2-3)]. An overview of the proposed control system is presented in Fig. 3, where the following sub-systems are depicted:

- Control of the Average Capacitor Voltage

- Control of the voltage imbalance in the capacitors
- Circulating Current Control.

- Generator-side Control System.

- Grid-side Control System.

- Single Cell Control and Modulation.

The control systems have been designed using the root-locus method and the transfer functions obtained from (3). The circulating current loops have been designed with a bandwidth of about $100 \mathrm{~Hz}$ and the outer voltage control systems with a bandwidth of $\approx 5 \mathrm{~Hz}$. A summary of the proposed controllers is shown in Table I with the designed closed-loop bandwidth $(\mathrm{Hz})$ indicated by $f_{n}$.

\begin{tabular}{|c|c|c|}
\hline CONTROL LOOP & TYPE & $f_{n}[\mathrm{~Hz}]$ \\
\hline Average Voltage & 1 PI Controller & 10 \\
\hline Cap.Voltage Balancing & 4 PI Controllers (outer control loops) & 5 \\
\hline Machine-side Current & 2 PI Controllers (d-q coordinates) & 100 \\
\hline Grid-side current & 2 Resonant Controllers & 100 \\
\hline Circulating Currents & 4 P Controllers (inner control loops) & 100 \\
\hline Single-Cell Voltage & 27 Proportional Controller & 2 \\
\hline
\end{tabular}

The generator is regulated using standard field orientated control techniques, implemented in a synchronous rotating $\mathrm{d}-\mathrm{q}$ axis. The average value of the cell-capacitor voltages is regulated by imposing an additional component to the generator torque current (i.e. similar to the conventional control methodologies used in back-to-back converters [4]). The grid-side control system regulates the grid-connected operation, power factor regulation and provides FRT compliance.

\section{A. Modelling and Control of the Generator-Side: MPPT algorithm}

The modelling of WECSs and Permanent Magnets Synchronous Generators (PMSGs) have been extensively discussed in the literature [3], [4], [14], [15]. In steady state, the wind turbine operates using an MPPT algorithm, where the generator torque is regulated as:

$$
T_{e}=k_{\text {opt }} \omega_{m}^{2} \rightarrow P_{m}=k_{\text {opt }} \omega_{m}^{3}
$$

where $k_{\text {opt }}$ is a constant that depends on the blade aerodynamics the gear box ratio and the wind turbine parameters. As presented in [14], the torque-current relationship for a PMSG considering orientation along the rotor flux is: 


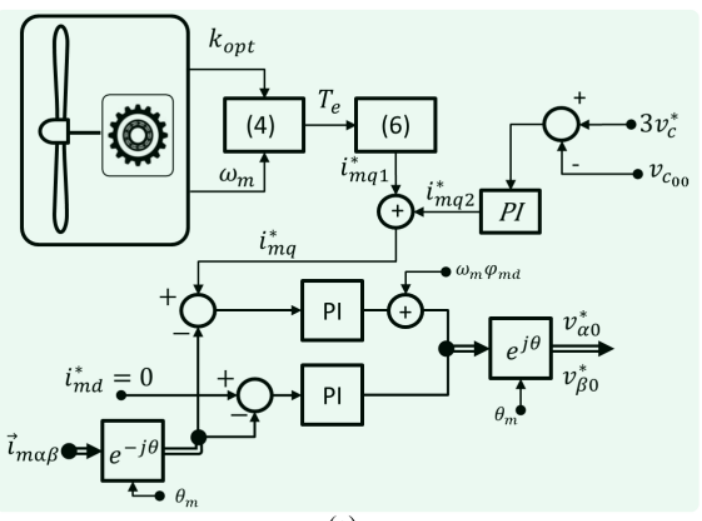

(a)

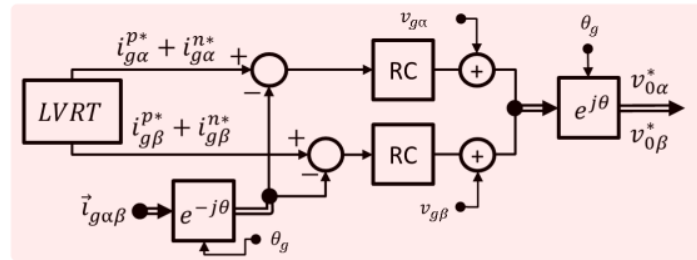

(d)

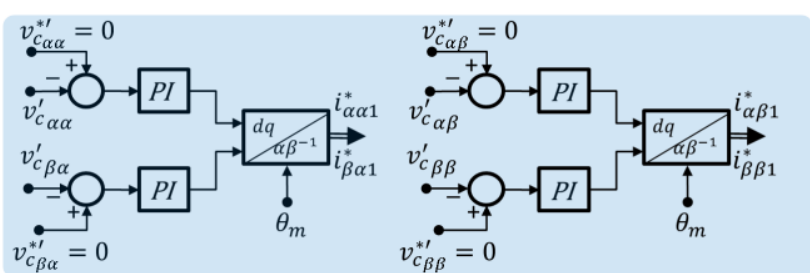

(b)

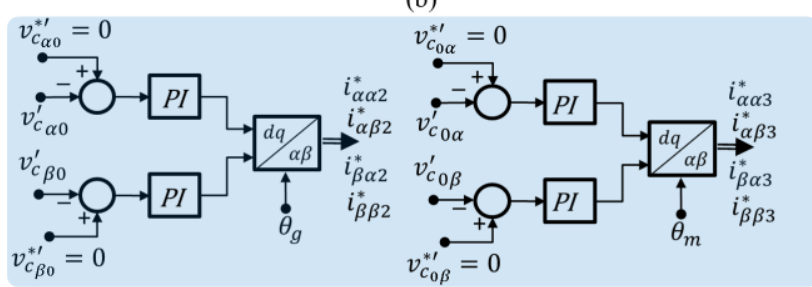

(c)

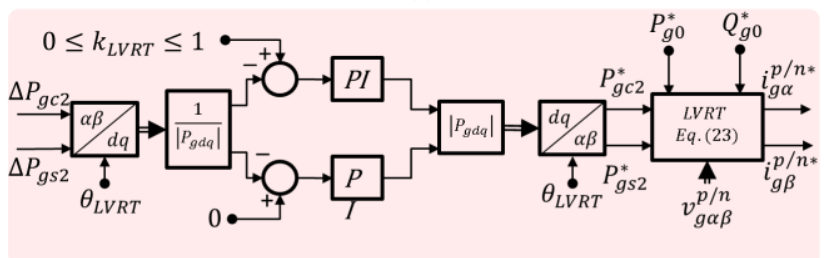

(e)

Fig. 4: Amplified view of (a) Generator-side control system. (b) Intra-SC capacitor voltage balancing. (c) Inter-SC capacitor voltage balancing. (d) Grid-side control system. (e) LVRT control system.

$$
T_{e}=\frac{3}{2} p \psi_{m r} i_{m q}
$$

where $p$ represents the number of pole-pairs in the generator, the PMSG rotor flux is denoted by $\psi_{m r}$ and the generator torque current is $i_{m q}$. Replacing (4) in (5), the PMSG current reference for MPPT purposes is calculated as follows:

$$
i_{m q 1}^{*}=\frac{2}{3} \frac{k_{o p t} \omega_{m}^{2}}{p \psi_{m r}}
$$

The proposed control system is presented in Fig. 4(a) where it is shown that the total PMSG torque current is composed of two elements. $i_{m q 1}^{*}$ in (6) and a second component $i_{m q 2}^{*}$ required to regulate one of the voltage components in the $\mathrm{M}^{3} \mathrm{C}$. This is discussed later.

\section{B. Control of the $M 3 C$}

\section{1) Average Capacitor Voltage Control}

A single cluster is used to analyse the energy stored in the $\mathrm{M}^{3} \mathrm{C}$ capacitors [see Fig. 2(b)]. Neglecting internal losses, the cluster energy $W_{x y}$ is defined as the integral of the cluster power, which is related to the capacitor voltages using:

$$
W_{x y}=\frac{c}{2} \sum_{n} v_{C i}^{2}
$$

Assuming that in each cell the capacitor voltage is operating around a quiescent point $v_{c i}^{0} \approx v_{c}^{*}$, a small signal model of (7) can be derived as:

$\Delta W_{x y}=\sum_{n} \frac{\partial W_{x y}}{\partial v_{c i}} \Delta v_{c i}=C v_{c}^{*} \sum_{n} \Delta v_{c i}=C v_{c}^{*} \Delta v_{C_{x y}}$

The relationship between the power and the energy of the cluster is obtained from (8) as:

$\Delta P_{x y}=\frac{d \Delta W_{x y}}{d t}=C v_{c}^{*} \frac{d \Delta v C_{x y}}{d t}$

Where: $n$ is the number of cells in the cluster, $x \in\{a, b, c\}$, $y \in\{r, s, t\}, P_{x y}$ represents the cluster power, $v_{C_{x y}}$ is the addition of all the capacitor voltages in one cluster, $v_{C}^{*}$ is the reference voltage of each cell [assumed as the quiescent point in (8)], $C$ represents the capacitance of each capacitor and $W_{x y}$ symbolises the cluster energy.

Using (9), neglecting initial conditions and assuming operation around the aforementioned quiescent point (i.e. $\left.v_{C_{x y}} \approx n v_{C}^{*}+\Delta v_{C_{x y}}\right)$, the 9 cluster-capacitor voltages $\left(v_{C_{x y}}\right)$ are obtained as:

$\left[\begin{array}{lll}v_{c_{a r}} & v_{c_{a s}} & v_{c_{a t}} \\ v_{c_{b r}} & v_{c_{b s}} & v_{c_{b t}} \\ v_{c_{c r}} & v_{c_{c s}} & v_{c_{c t}}\end{array}\right]=\frac{1}{c v_{c}^{*}} \int_{0}^{t}\left[\begin{array}{lll}\Delta P_{a r} & \Delta P_{a s} \Delta P_{a t} \\ \Delta P_{b r} & \Delta P_{b s} \Delta P_{b t} \\ \Delta P_{c r} & \Delta P_{c s} \Delta P_{c t}\end{array}\right] d t+n v_{c}^{*}\left[\begin{array}{lll}1 & 1 & 1 \\ 1 & 1 & 1 \\ 1 & 1 & 1\end{array}\right]$

In $a b c$ coordinates, the powers in each cluster are calculated using $P_{x y}=v_{x y} i_{x y}$ (see Fig. 2). Applying the twostage $\alpha \beta 0$ transformation to (10) yields:

$\left[\begin{array}{ccc}v_{c_{\alpha \alpha}} & v_{c_{\beta \alpha}} & v_{c_{0 \alpha}} \\ v_{c_{\alpha \beta}} & v_{c_{\beta \beta}} & v_{c_{0 \beta}} \\ v_{c_{\alpha 0}} & v_{c_{\beta 0}} & v_{c_{00}}\end{array}\right]=\frac{1}{C v_{c}^{*}} \int_{0}^{t}\left[\begin{array}{ll}\Delta P_{\alpha \alpha} \Delta P_{\beta \alpha} \Delta P_{0 \alpha} \\ \Delta P_{\alpha \beta} \Delta P_{\beta \beta} \Delta P_{0 \beta} \\ \Delta P_{\alpha 0} \Delta P_{\beta 0} \Delta P_{00}\end{array}\right] d t+\left[\begin{array}{ccc}0 & 0 & 0 \\ 0 & 0 & 0 \\ 0 & 0 & 3 n v_{c}^{*}\end{array}\right]$

In steady state, when the incremental powers $\Delta P_{x y} \approx 0$ and the capacitor voltages in each cell are equal to $v_{c}^{*}$, the converter is operating in "balanced" conditions. Consequently, most of the voltages (i.e. $v_{c_{\alpha \alpha}}, v_{c_{\beta \alpha}}, v_{c_{0 \alpha}}, v_{c_{\alpha \beta}}, v_{c_{\beta \beta}}, v_{c_{0 \beta}}$, $\left.v_{c_{\alpha 0}}, v_{c_{\beta 0}}\right)$ in (11) are equal to zero. The only exception is the component $v_{c_{00}}=3 n v_{C}^{*}$. This component is related to the active power flowing into the converter $P_{00}$, which can be calculated as the difference between the input and output power, i.e.:

$\Delta P_{00}=\frac{1}{3}\left(\Delta P_{\text {in }}-\Delta P_{\text {out }}\right)=\frac{1}{3}\left(\frac{3}{2} v_{m q} \Delta i_{m q}-\Delta P_{\text {out }}\right) \approx$
$C v_{c}^{*} \frac{d \Delta v_{c_{00}}}{d t}$

where $v_{m q}$ and $i_{m q}$ are the q-axis generator-side voltage and 
current respectively. As shown in (12), the power term $\Delta P_{00}$ is regulated using incremental changes in the generator torque current. The term $\Delta P_{\text {out }}$ is considered a disturbance and can be neglected, or used as a feed-forward term, for control purposes. Therefore, for energy balancing purposes, an incremental torque current $\Delta i_{m q 2}$ can be calculated as:

$$
\Delta i_{m q 2}=2 \frac{C v_{c}^{*}}{v_{m q}} \frac{d \Delta v_{c_{00}}}{d t}
$$

In this work, the control system regulates the average voltage of all capacitors by using $\Delta i_{m q 2}^{*}$, i.e.:

$$
\Delta i_{m q 2}^{*}=-G_{P I}(s) \Delta v_{c_{00}}=G_{P I}(s)\left(3 n v_{c}^{*}-v_{c_{00}}\right)
$$

where $G_{P I}(s)$ is the transfer function of a PI controller [see Fig. 4(a)].

\section{2) Control Systems for Balancing the Cap. Voltages}

The mean component of the eight voltages in (11) (i.e. $v_{c_{\alpha \alpha}}$, $v_{c_{\beta \alpha}}, v_{c_{0 \alpha}}, v_{c_{\alpha \beta}}, v_{c_{\beta \beta}}, v_{c_{0 \beta}}, v_{c_{\alpha 0}}, v_{c_{\beta 0}}$ ) have to be regulated to zero in order to balance the converter. The voltage terms $v_{\mathrm{c}_{\alpha \alpha}}$, $v_{c_{\beta \alpha}}, v_{c_{\alpha \beta}}, v_{c_{\beta \beta}}$ represent capacitor voltage imbalances inside a sub-converter (Intra-SC). The voltage components $v_{c_{0 \alpha}}$, $v_{c_{0 \beta}}, v_{c_{\alpha 0}}, v_{c_{\beta 0}}$ represent imbalances between SCs (Inter-SC). All these voltage terms could be regulated using either circulating currents or the common mode voltage $v_{N n}$ (see [12], [13]). However, the injection of a common-mode voltage could lead to large capacitor-voltage oscillations if a third order harmonic common mode voltage is used, and the generator frequency is one third of the grid frequency $(16.3 \mathrm{~Hz}$ for a $50 \mathrm{~Hz}$ grid) [12]. Therefore, in this work circulating currents alone have been used to regulate the unbalanced voltage components.

The power components in (11) can be expressed as a function of the voltages and currents of the system referred to the two-stage $\alpha-\beta-0$ domain (see [12]). Neglecting the voltage drop in the inductance, using $v_{N n}=0$ and denoting "o" as the Hadamard (element by element) product, the powers in the $a b c$-rst domain are obtained from (1) as:

$\left[P_{x y}\right]=\left(\left[v_{m x}\right]-\left[v_{g y}\right]\right) \circ\left[i_{x y}\right]$

Applying the two-stage transformation to (15) and after some manipulations/simplifications (see [12]), the power in the two-stage $\alpha \beta 0$ domain is obtained. For instance, the power component $P_{\alpha \alpha}$ can be expressed as:

$P_{\alpha \alpha}=\frac{1}{3}\left(v_{m \alpha} i_{g \alpha}-v_{g \alpha} i_{m \alpha}\right)+\frac{1}{\sqrt{6}}\left(v_{m \alpha} i_{\alpha \alpha}-v_{m \beta} i_{\beta \alpha}\right)-$

$\frac{1}{\sqrt{6}}\left(v_{g \alpha} i_{\alpha \alpha}-v_{g \beta} i_{\alpha \beta}\right)$

This component is required to obtain the incremental power $\Delta P_{\alpha \alpha}$, used to regulate $v_{c_{\alpha \alpha}}$ in (11). At this point, some simplifications to (16) can be considered. If the rotational speed of the WECSs is restricted within a suitable range, then the term $\left(v_{m \alpha} i_{g \alpha}-v_{g \alpha} i_{m \alpha}\right)$ possess components of frequencies $\omega_{g} \pm \omega_{m}$. If the dc-link capacitors are properly designed (see Section III.E) these frequencies do not produce large oscillations in the capacitor voltages.

Therefore, in this work, the circulating currents are designed to generate a non-zero mean active power term in the power $P_{\alpha \alpha}$ which can be used to regulate any possible dc-drift or close-to-dc components in this power term. The drift could be produced, for instance, by non linearities in the converter cells, offsets in the measured signals, etc. Notice that, due to the integral effect produced in the capacitors, even small dc components in the powers of (11) could produce significant voltage imbalances.

Imposing a negative sequence of frequency $\omega_{m}$ (i.e. $\underline{i}_{\alpha}=$ $i_{\alpha \alpha}-j i_{\beta \alpha}$, with $\left.i_{\alpha \alpha}=i_{c c} \cos \theta_{m}, i_{\beta \alpha}=i_{c c} \sin \theta_{m}\right)$ in the circulating currents interacting with $P_{\alpha \alpha},(16)$ yields to:

$$
\begin{gathered}
P_{\alpha \alpha}=\overbrace{\frac{v_{m} i_{c c}}{\sqrt{6}}\left(\cos ^{2} \theta_{m}+\sin ^{2} \theta_{m}\right)}^{D C \text { Component }}-\frac{1}{\sqrt{6}} \overbrace{\left(v_{g \alpha} i_{\alpha \alpha}-v_{g \beta} i_{\alpha \beta}\right)}^{A C \text { Components } \omega_{g} \pm \omega_{m}} \\
+\frac{1}{3} \overbrace{\left(v_{m \alpha} i_{g \alpha}-v_{g \alpha} i_{m \alpha}\right)}^{A C \text { Components } \omega_{g} \pm \omega_{m}} \rightarrow \frac{d \Delta v_{c \alpha \alpha}^{\prime}}{d t}=\frac{\Delta P_{\alpha \alpha}^{\prime}}{C v_{c}^{*}} \approx k_{1} v_{m} i_{c c}
\end{gathered}
$$

where $k_{1}=\frac{1}{\sqrt{6} C v_{c}^{*}}$ and $v_{c_{\alpha \alpha}}^{\prime}$ is a filtered version of $v_{c_{\alpha \alpha}}$. Filtering the AC components in (17) leads to the second expression, which is applied to control the component $v_{c_{\alpha \alpha}}^{\prime}$.

a. Intra-SC balancing current reference calculation:

The same methodology (i.e. neglecting high-frequency components and considering $v_{N n}=0$ ) is used to analyse the dynamic of the incremental voltages $\Delta v_{c_{\alpha \alpha}}^{\prime}, \Delta v_{C_{\alpha \beta}}^{\prime}, \Delta v_{C_{\beta \alpha}}^{\prime}$ and $\Delta v_{C_{\beta \beta}}^{\prime}$. This yields to:

$\frac{d}{d t}\left[\begin{array}{l}\Delta v_{c_{\alpha \alpha}}^{\prime} \\ \Delta v_{c_{\alpha \beta}}^{\prime} \\ \Delta v_{c_{\beta \alpha}}^{\prime} \\ \Delta v_{c_{\beta \beta}}^{\prime}\end{array}\right]=k_{1}\left\{\left[\begin{array}{cccc}v_{m \alpha} & 0 & -v_{m \beta} & 0 \\ 0 & v_{m \alpha} & 0 & -v_{m \beta} \\ -v_{m \beta} & 0 & -v_{m \alpha} & 0 \\ 0 & -v_{m \beta} & 0 & -v_{m \alpha}\end{array}\right]\right\}\left[\begin{array}{l}\Delta i_{\alpha \alpha} \\ \Delta i_{\alpha \beta} \\ \Delta i_{\beta \alpha} \\ \Delta i_{\beta \beta}\end{array}\right]$

Therefore, a negative-sequence circulating current component of frequency $\omega_{m}$ leads to a non-zero mean active power value, which is manipulated to drive the average component of the unbalanced voltages of (18) to zero. Notice that in (18) circulating currents of frequency $\omega_{g}$ could be also applied to the $\mathrm{M}^{3} \mathrm{C}$ to generate a non-zero mean active power. However, in this application it is assumed that the WECS has to be synchronised to the grid before being connected. Therefore, before synchronisation well-regulated grid voltages are not available in the cluster voltages and better results can be achieved by using the generator voltages and circulating currents of frequency $\omega_{m}$. As shown in Fig. 4(b), PI controllers regulate the average component of the Intra-SC terms to zero by imposing circulating current references of negative-sequence $\omega_{m}$.

b. Inter-SC balancing current reference calculation

A similar process is carried out to analyse the Inter-SC unbalanced voltages. The dynamics of the unbalanced incremental voltage components are described by:

$\frac{d}{d t}\left[\begin{array}{l}\Delta v_{c_{\alpha 0}}^{\prime} \\ \Delta v_{c_{\beta 0}}^{\prime} \\ \Delta v_{c_{0 \alpha}}^{\prime} \\ \Delta v_{c_{0 \beta}}^{\prime}\end{array}\right]=\frac{1}{\sqrt{3} c v_{c}^{*}}\left[\begin{array}{cccc}-v_{g \alpha} & -v_{g \beta} & 0 & 0 \\ 0 & 0 & -v_{g \alpha} & -v_{g \beta} \\ v_{m \alpha} & 0 & v_{m \beta} & 0 \\ 0 & v_{m \alpha} & 0 & v_{m \beta}\end{array}\right]\left[\begin{array}{c}\Delta i_{\alpha \alpha} \\ \Delta i_{\alpha \beta} \\ \Delta i_{\beta \alpha} \\ \Delta i_{\beta \beta}\end{array}\right]$

The circulating current references are controlled to regulate the Inter-SC unbalanced voltages to zero using PI controllers. 


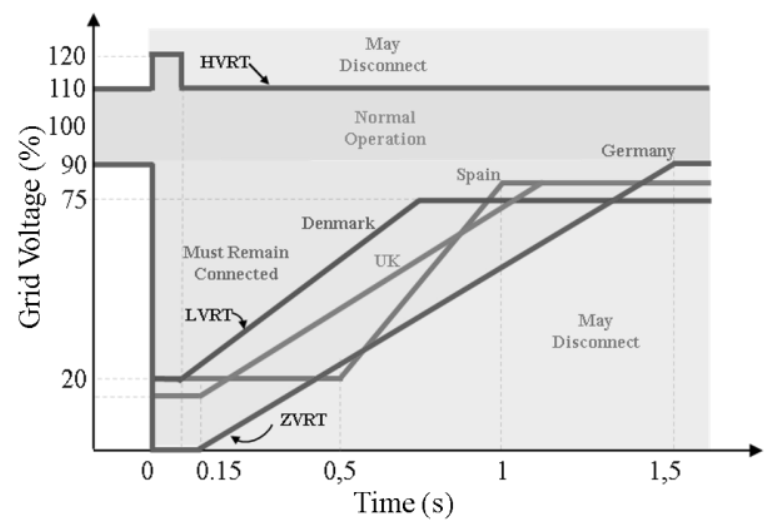

(a)

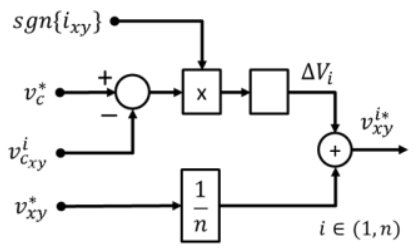

(b)

Fig. 5: (a) FRT requirements. Voltage profile for faults in Germany, Denmark, UK and Spain. (b) Single cell capacitor voltage control.

In this case, the current references are referred into positive sequence reference frames using the angles $\theta_{m}$ and $\theta_{g}$, as shown in Fig. 4(c).

\section{3) Circulating Current Control}

The composite circulating current references are obtained considering the superposition of the Inter-SC and Intra-SC circulating current references. The equation for the circulating current reference $i_{\alpha \alpha}^{*}$, for example, is:

$\Delta i_{\alpha \alpha}^{*}=\Delta i_{\alpha \alpha 1}^{*}+\Delta i_{\alpha \alpha 2}^{*}+\Delta i_{\alpha \alpha 3}^{*}$

Similar expressions can be used to obtain the current references $\Delta i_{\beta \alpha}^{*}, \quad \Delta i_{\alpha \beta}^{*}$ and $\Delta i_{\beta \beta}^{*}$. In the experimental implementation, the voltage commands required to regulate the four circulating currents are obtained using proportional controllers:

$\left[\begin{array}{cc}v_{\alpha \alpha}^{*} & v_{\beta \alpha}^{*} \\ v_{\alpha \beta}^{*} & v_{\beta \beta}^{*}\end{array}\right]=-k_{c c}\left(\left[\begin{array}{cc}i_{\alpha \alpha}^{*} & i_{\beta \alpha}^{*} \\ i_{\alpha \beta}^{*} & i_{\beta \beta}^{*}\end{array}\right]-\left[\begin{array}{cc}i_{\alpha \alpha} & i_{\beta \alpha} \\ i_{\alpha \beta} & i_{\beta \beta}\end{array}\right]\right)$

where $k_{c c}$ is the proportional gain required to control the circulating currents with an appropriate dynamic response.

\section{Modelling and control of the Grid-Side: LVRT algorithm}

In the last years, stringent grid codes have been enforced for grid-connection of WECS, focusing on power quality, power controllability, and Low Voltage Ride Through (LVRT) capability [16]. As shown in Fig. 5(a), several national grid codes for LVRT demand that WECSs remain connected in the presence of voltage swell-sag, providing grid-voltage support. For the implementation of LVRT control systems, the measured currents and voltages must be separated into positive and negative sequence components to eliminate the power oscillations in the active -or reactive- power injected into the grid. As reported in [17], the power supplied to the grid and the grid voltages/currents are related by (22):
$\left[\begin{array}{l}P_{g_{0}} \\ Q_{g_{0}} \\ P_{g_{s 2}} \\ P_{g_{c 2}}\end{array}\right]=\left[\begin{array}{cccc}v_{g \alpha}^{p} & v_{g \beta}^{p} & v_{g \alpha}^{n} & v_{g \beta}^{n} \\ v_{g \beta}^{p} & -v_{g \alpha}^{p} & v_{g \beta}^{n} & -v_{g \alpha}^{n} \\ v_{g \beta}^{n} & -v_{g \alpha}^{n} & -v_{g \beta}^{p} & v_{g \alpha}^{p} \\ v_{g \alpha}^{n} & v_{g \beta}^{n} & v_{g \alpha}^{p} & v_{g \beta}^{p}\end{array}\right]\left[\begin{array}{l}i_{g \alpha}^{p} \\ i_{g \beta}^{p} \\ i_{g \alpha}^{n} \\ i_{g \beta}^{n}\end{array}\right]$

Where the superscripts $p$, and $n$ symbolises the positive and negative-sequence components, respectively. The terms " $P_{g c 2}$ " and " $P_{g s 2}$ " represent double frequency oscillations in active power that can be mitigated using the following references:

$\left[\begin{array}{c}i_{g \alpha}^{p *} \\ i_{g \beta}^{p *} \\ i_{g \alpha}^{n *} \\ i_{g \beta}^{n *}\end{array}\right]=\left[\begin{array}{cccc}v_{g \alpha}^{p} & v_{g \beta}^{p} & v_{g \alpha}^{n} & v_{g \beta}^{n} \\ v_{g \beta}^{p} & -v_{g \alpha}^{p} & v_{g \beta}^{n} & -v_{g \alpha}^{n} \\ v_{g \beta}^{n} & -v_{g \alpha}^{n} & -v_{g \beta}^{p} & v_{g \alpha}^{p} \\ v_{g \alpha}^{n} & v_{g \beta}^{n} & v_{g \alpha}^{p} & v_{g \beta}^{p}\end{array}\right]^{-1}\left[\begin{array}{c}P_{g}^{*} \\ Q_{g}^{*} \\ P_{g_{s 2}}^{*} \\ P_{g c}^{*}\end{array}\right]$

If the grid currents calculated from (23), considering $P_{g_{c 2}}^{*}=0, P_{g_{s 2}}^{*}=0$, are imposed by the control system, the oscillatory active power consumed by the filter inductance is supplied by the $\mathrm{M}^{3} \mathrm{C}$. These oscillations are calculated as [17]:

$\Delta P_{g c 2}=\left[2 R_{g}^{\prime}\left(i_{g \alpha}^{p} i_{g \alpha}^{n}+i_{g \beta}^{p} i_{g \beta}^{n}\right)+2 \omega_{g} L_{g}^{\prime}\left(i_{g \alpha}^{p} i_{g \beta}^{n}-i_{g \beta}^{p} i_{g \alpha}^{n}\right)\right]$

$\Delta P_{g s 2}=\left[2 R_{g}\left(i_{g \alpha}^{p} i_{g \beta}^{n}-i_{g \beta}^{p} i_{g \alpha}^{n}\right)+2 \omega_{g} L_{g}^{\prime}\left(-i_{g \alpha}^{p} i_{g \alpha}^{n}-i_{g \beta}^{p} i_{g \beta}^{n}\right)\right]$

Where $L_{g}^{\prime}$ and $R_{g}^{\prime}$ are the equivalent inductance and resistance of the grid. The equivalent grid-side inductance is $L_{g}^{\prime}=(1 / 3) L_{b}+L_{g}$, where the term $(1 / 3) L_{b}$ corresponds to the parallel connection of the three cluster inductors connected to each of the grid phases, and the term $L_{g}$ represents any additional inductance connected between the $\mathrm{M}^{3} \mathrm{C}$ output and the grid. As discussed in the previous sections, avoiding voltage oscillations is important in modular multilevel converters where the capacitors are floating. Therefore, to avoid increasing the voltage ripple in the converter, the power oscillations produced in the inductances, i.e. the values of $\Delta P_{g c 2}^{*}$ and $\Delta P_{g s 2}^{*}$ [see (24)-(25)], have to be supplied by the grid. Then, the values of $\Delta P_{\mathrm{gc} 2}$ and $\Delta P_{g_{s 2}}$ should be considered in the calculation of the reference current in (23), i.e. $P_{g_{c 2}}^{*}=-\Delta P_{g c 2}, P_{g_{s 2}}^{*}=-\Delta P_{g s 2}$.

In this section, an enhanced LVRT algorithm, for $\mathrm{M}^{3} \mathrm{C}$ applications, is proposed. The control diagram is shown in Fig. 4(d) and Fig. 4(e). The double frequency active power components $\left(\Delta P_{g c 2}\right.$ and $\left.\Delta P_{g s 2}\right)$ calculated using (24)-(25) are referred to a synchronous frame rotating at twice the grid frequency. Then, PI controllers are used to regulate $\Delta P_{g_{s 2}}$ and $\Delta P_{g_{c 2}}$ in $d q$ coordinates, obtaining the powers $P_{g s 2}^{*}$ and $P_{g c 2}^{*}$ used in (23) [see Fig.4(e)]. To implement (23) the positive and negative components of the currents are estimated using the Delay Signal Cancellation (DSC) method proposed in [18]. Finally, using (23) and the control system shown in Fig. 5, the current references $i_{g \alpha}^{p *}, i_{g \beta}^{p *}, i_{g \alpha}^{n *}$ and $i_{g \beta}^{n *}$ are obtained and regulated using Resonant Controllers. The complete control system for the grid converter is presented in Fig. 4(d).

\section{Single-Cell Control}

The voltage references obtained in the control loops presented above $\left(v_{\alpha \alpha}^{*}, v_{\beta \alpha}^{*}, v_{\alpha \beta}^{*}, v_{\beta \beta}^{*}, v_{\alpha 0}^{*}, v_{\beta 0}^{*}, v_{0 \alpha}^{*}\right.$ and $\left.v_{0 \beta}^{*}\right)$ are transformed to the natural reference frame using the inverse two-stage $\alpha \beta 0$ transform. Then, references $v_{\alpha r}^{*}, v_{b r}^{*}$, 
$v_{c r}^{*}, v_{a s}^{*}, v_{b s}^{*}, v_{c s}^{*}, v_{a t}^{*}, v_{b t}^{*}, v_{c t}^{*}$ are obtained for each cluster [see (1)].

An additional loop (based on a proportional controller) is utilised to regulate the dc-link voltage of each cell within a cluster [19]. The capacitor voltage of each cell $i[i \in(1, n)]$ is compared to the desired value $v_{c}^{*}$. The resulting error is multiplied by the sign of the cluster current (and by the gain $k_{n}$ ) producing an incremental voltage $\Delta V$ which is added to the cell reference voltage $v_{x y}^{*} / n$. The modulation index in each cell is then calculated considering its dc-link voltage value [see Fig. 5(b)]. Finally, phase-shifted PWM is used to synthesise the voltage references. This modulation is simple to implement in a commercial FPGA-based control platform and produces power losses evenly distributed among the cells of the same cluster. Moreover, phase-shifted unipolar modulation generates an output switching frequency of $2 n$ times the carrier frequency [19].

\section{E. Dimensioning of the $M^{3} C$}

To select the correct value of cell capacitance to be utilised in the implementation of the $\mathrm{M}^{3} \mathrm{C}$ clusters is important [20], [21]. This capacitance has to be designed to buffer the peakto-peak energy variations generated by the variable speed operation, maintaining the voltage oscillations inside an appropriate range.

In natural $a b c$, rst frames, the instantaneous power in each cluster is obtained from the Hadamard product of (15) as:

$$
\left[P_{x y}\right]=\left(\left[v_{m x}\right]-\left[v_{g y}\right]\right) \circ(1 / 3)\left(\left[i_{m x}\right]+\left[i_{g y}\right]\right)
$$

Where $x \in\{a, b, c\}$ and $y \in\{r, s, t\}$. It is assumed that a third of the machine/grid phase currents is circulating in each cluster. Expanding (26), power terms with four oscillating frequencies are obtained: a term of frequency $2 \omega_{m}$; a term of frequency $2 \omega_{g}$; and two power terms of frequencies $\omega_{g} \pm \omega_{m}$ (produced by the input/output cross products, i.e. $v_{m x} i_{g y}-$ $\left.v_{g y} i_{m x}\right)$. Using (9) the variation in the energy stored in the capacitors could be obtained from these four power terms as:

$\Delta W_{x y}=C v_{C}^{*} \Delta v_{C x y}=\int_{0}^{t}\left(\left[P_{x y 1}\right]_{\omega=2 \omega_{m}}+\left[P_{x y 2}\right]_{\omega=2 \omega_{g}}+\right.$
$\left.\left[P_{x y 3}\right]_{\omega=\omega_{g}-\omega_{m}}+\left[P_{x y 3}\right]_{\omega=\omega_{g}+\omega_{m}}\right) d t$

As discussed in several publications, the capacitor voltage oscillations in the $\mathrm{M}^{3} \mathrm{C}$ are more difficult to control when the input/output frequencies have similar values, i.e. $\omega_{g}-\omega_{m}$ is relatively small [22]. From (27) the cluster capacitance could be calculated as:

$C=k_{c} \frac{\Delta W_{x y}}{\Delta v_{c_{x y}} v_{c}^{*}}$

where $\Delta W_{x y}$ is the energy ripple, $\Delta v_{C_{x y}}$ is the maximum allowable capacitor voltage ripple and $k_{c}$ represents an additional safety factor [21]. In this application, $k_{c}$ is selected to slightly oversize the capacitance considering that during LVRT the energy fluctuation in the capacitors could be increased.

In this work, it is assumed that $f_{g}$ is $50 \mathrm{~Hz}$ and the generator is operating between $10-40 \mathrm{~Hz}$. Furthermore, the capacitor

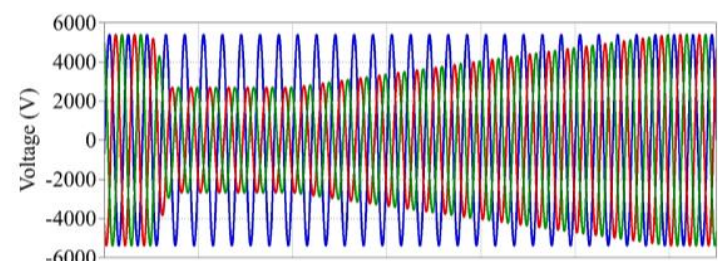

(a)

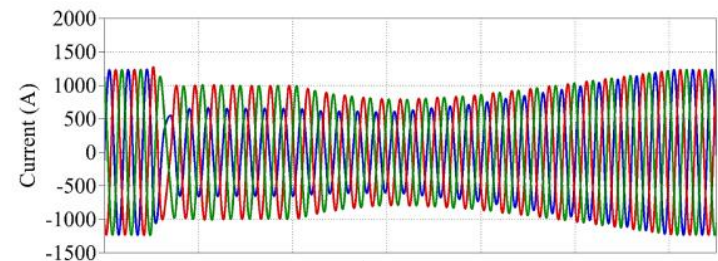

(b)

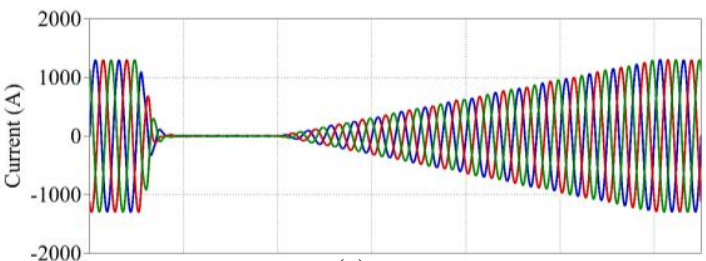

(c)

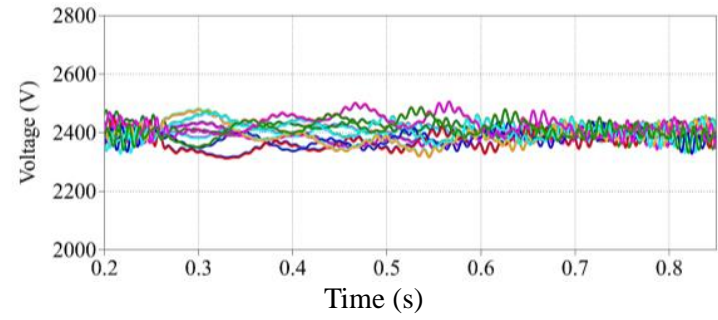

(d)

Fig. 6: Simulation results during grid faults. (a) Grid Voltages. (b) Grid currents. (c) Generator-side currents. (d) Cluster capacitor voltages.

voltage could be regulated between $100 \mathrm{~V}-155 \mathrm{~V}$ with a $\Delta v_{C_{x y}}$ of about $15 \mathrm{~V}$ peak $(\approx 10 \%$ of $155 \mathrm{~V})$.

The value of the cluster inductance is relatively simple to calculate by imposing a limit in the ripple of the current (usually set to $10 \%-15 \%$ of the nominal value). This value is calculated as [20][23]:

$L_{b}=\frac{0.5\left(\frac{v_{c}^{*}}{n}+\Delta v_{c_{x y}}\right)}{\Delta i_{x y} f_{s w}}$

where $\Delta i_{x y}$ is the maximum allowable cluster current ripple and $f_{s w}$ is the output switching frequency.

\section{Simulation Results}

A simulation model considering a $\mathrm{M}^{3} \mathrm{C}$ composed of five cells per cluster has been implemented using the software PLECS $\AA$. The design of the high-power converter is depicted in Table II. The parameters of the experimental system are also shown in that Table. It is assumed that a PMSG is connected to the converter input and that medium voltage IGBT devices are used in the $\mathrm{M}^{3} \mathrm{C}$ implementation (see [24], [25]), therefore each capacitor voltage is regulated to $2.4 \mathrm{kV}$. For the simulation work the cluster inductances are designed to produce a maximum cluster current ripple of $10 \%$. The performance of the proposed control strategy is tested for a Dip Type C (see [16]), with two of the phases reducing their voltages to a $50 \%$ of the nominal value [see Fig. 6(a)]. 
TABLE II: SimUlation \& EXPERIMENTAL SETUP PARAMETERS

\begin{tabular}{c|c|c}
\hline Parameters & Simulation & Experimental setup \\
\hline Nominal Power & $10 \mathrm{MVA}$ & $6 \mathrm{kVA}$ \\
\hline Cells per branch & 5 & 3 \\
\hline Input Voltage/Freq. & $5.4 \mathrm{kV} / 10-40 \mathrm{~Hz}$ & $200 \mathrm{~V} / 10-40 \mathrm{~Hz}$ \\
\hline Branch Inductor & $1.3 \mathrm{mH}$ & $2.5 \mathrm{mH}$ \\
\hline Single cell $C$. & $8 \mathrm{mF}$ & $4.7 \mathrm{mF}$ \\
\hline Capacitor Voltage & $2.4 \mathrm{kV}$ & $100-155 \mathrm{~V}$ \\
\hline Output Voltage/Freq. & $5.4 \mathrm{kV} / 50 \mathrm{~Hz}$ & $185 \mathrm{~V} / 50 \mathrm{~Hz}$ \\
\hline Switching frequency & $0.7 \mathrm{kHz}$ & $2.5 \mathrm{kHz}$ \\
\hline
\end{tabular}

When the fault is applied, the active power supplied to the grid is reduced to fulfill the LVRT requirements. As stated in (23), the LVRT control algorithm regulates unbalanced gridcurrents to mitigate active power oscillations and to provide reactive power injection, [see Fig. 6(b)]. As a consequence of the fault, the power produced by the generator is reduced as well as the active power fed to the grid [see Fig. 6(c)]. Due to the temporary mismatch between the mechanical input power and the electrical output power, the generator speed could be increased. However, for Multi-MW WECS, the high inertia of the generator; the relatively short duration of the fault (in the milliseconds range); the use of pitch control in the WECS; and the feasibility of using a dc- voltage limiter in each cell reduce the possibility of having large voltage fluctuations in the capacitor voltages during LVRT conditions [see Fig. 6(d)]. Therefore, the control systems for generator-side and grid-side are decoupled during grid-voltage sags, and the dynamic at the machine-side of the $\mathrm{M}^{3} \mathrm{C}$ remain relatively unaffected [14].

\section{EXPERIMENTAL RESULTS}

Experimental results for the proposed control methodology have been obtained using a 27-power cell laboratory prototype composed of nine clusters, each comprising the series connection of 3 full-H-bridge modules and one inductor. A photograph of the system is presented in Fig. 7(a) and a diagram is illustrated in Fig. 7(b). Parameters of the experimental system are given in Table II. Because of hardware availability reasons, $2.5 \mathrm{mH}$ inductors are used in each cluster, bounding the ripple to about $13 \%$ of the maximum cluster current. The system is controlled using a Digital Signal Processor Texas Instrument TMS320C6713 board and 3 Actel ProAsic3 FPGA boards, equipped with 50 14-bit analogue-digital (A/D) channels. A unipolar phaseshifted PWM algorithm generates the 108 switching signals timed via an FPGA. Optical fibre connections transmit the switching signals to the gate drivers of the MOSFET switches. Two programmable AMETEK power supplies emulate the electrical grid and the PMSG. The wind turbine dynamics are programmed in the generator-side power supply (model CSW5550) to emulate a generator operating at variable speed, variable voltage. The grid-side of the $\mathrm{M}^{3} \mathrm{C}$ is connected to another power source (Model MX45), which can generate programmable grid sag-swell conditions. The classification of voltage sags presented in [26] (e.g. dip type A, B, etc.) is used in this work. The H-bridges used in the $\mathrm{M}^{3} \mathrm{C}$, have been implemented using MOSFET devices of 60A, $300 \mathrm{~V}$ each one. However, considering the nominal current of the generatorside CSW5550 power supply, the $\mathrm{M}^{3} \mathrm{C}$ maximum input

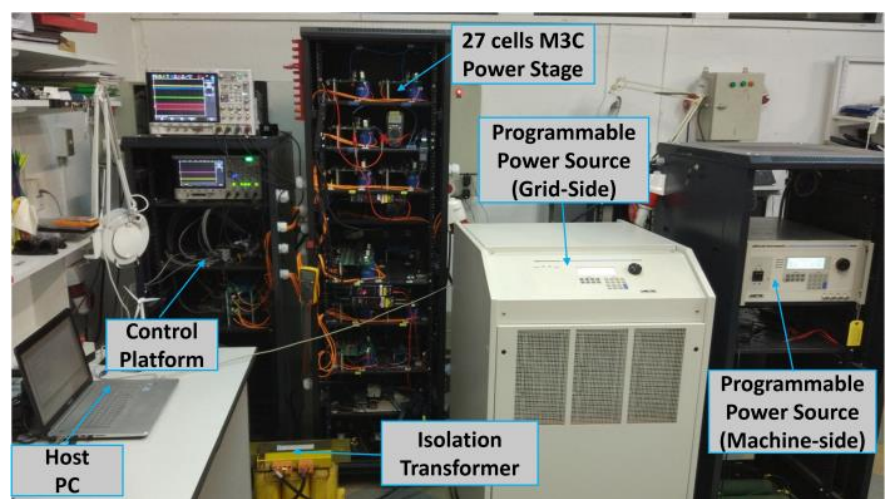

(a)

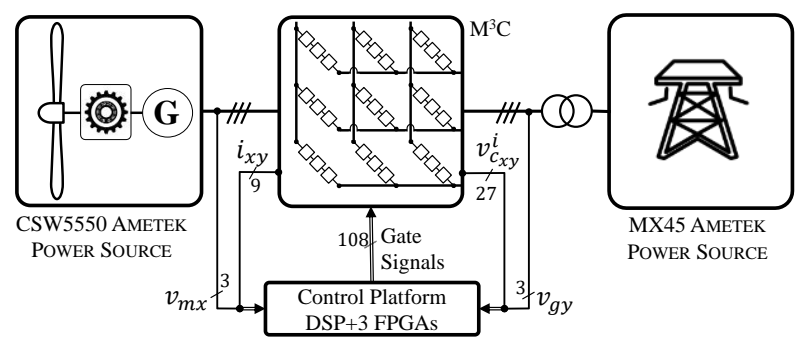

(b)

Fig. 7: Implemented System (a) Photograph. (b) Diagram.

current has been limited to about 18A peak. Finally, the open loop pre-charge method presented in [27] is used to pre-charge the 27 cell capacitors.

\section{A. Fixed Speed operation}

Steady state operation of the experimental prototype for fixed generator frequency is presented in Fig 8. Oscilloscope waveforms of the capacitor voltage $v_{c_{a r} 1}$, the input voltage $v_{m a b}$, the cluster voltage $v_{a r}$ and the grid voltage $v_{g r t}$ are presented from top to bottom in Fig. 8(a). The generator-side frequency is set to $40 \mathrm{~Hz}$, whereas, the grid frequency is $50 \mathrm{~Hz}$. The cluster voltage $v_{a r}$ modulates both (generator and grid) voltages and the different levels produced by the phase shifted modulation are observed. Signals measured using the A/D converters available in the control platform are also presented in Fig. 8(b)-(g). The input and output currents are controlled to $18 \mathrm{~A}$ (peak value), and are not much affected by the circulating currents produced by the balancing algorithms. As shown in Fig. 8(b) and Fig. 8(c), the input and output currents present low harmonic distortion $(T H D \approx 2 \%)$ and are balanced. The Inter-SC voltage ripple components $\left(v_{c 0 \alpha}, v_{c 0 \beta}\right.$, $\left.v_{c \alpha 0}, v_{c \beta 0}\right)$ are presented in Fig. 8(d), whereas the Intra-SCs ripple components $\left(v_{c \alpha \alpha}, v_{c \alpha \beta}, v_{c \alpha \beta}, v_{c \beta \beta}\right)$ are shown in Fig. $8(\mathrm{e})$. The eight unbalanced voltage components are successfully regulated inside a $\pm 5 \mathrm{~V}$ band. For this test, the average value of all the capacitor voltages is regulated to 100V [see Fig. 8(f)]. Fig. 8(g) illustrates the unity power factor operation of the system, in this case, injecting $4 \mathrm{~kW}$ into the grid.

\section{B. Variable Speed Operation}

The operation of a PMSG based variable-speed wind turbine is simulated using a wind speed profile. The frequency and voltage profiles obtained in this simulation are discretised and programmed in the input-side power supply (Model CSW- 


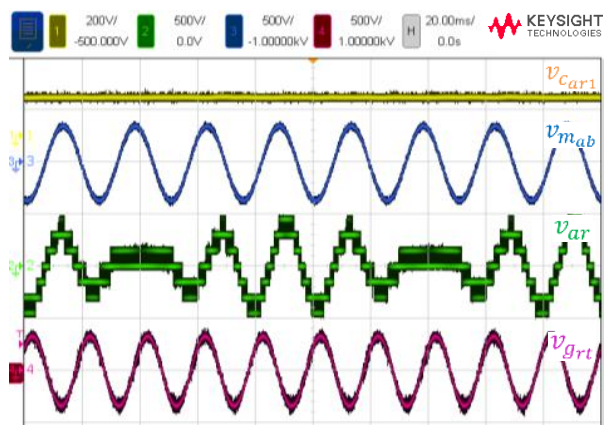

(a)

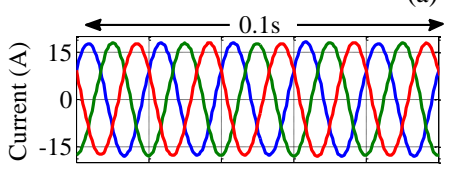

(b)

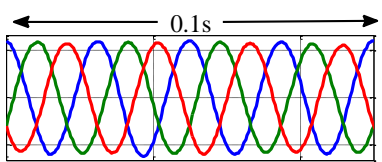

(c)

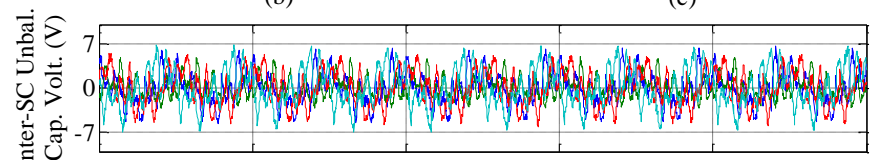

(d)

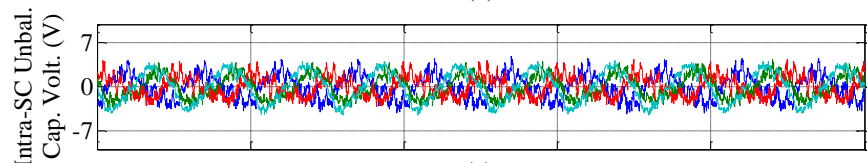

(e)

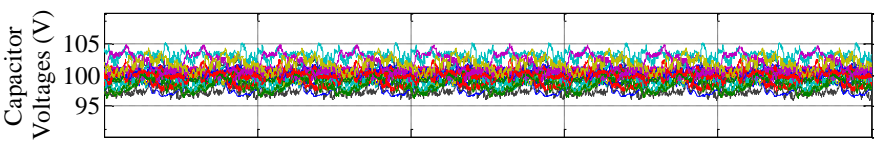

(f)

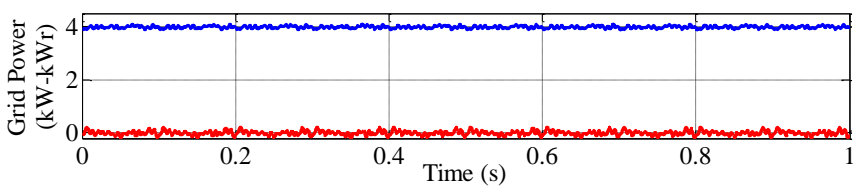

(g)

Fig. 8: Experimental results for fixed speed operation. (a) Oscilloscope waveforms operating at 150V. (b)-(g). Exp. results for $v_{C}^{*}=100 \mathrm{~V}$. (b) Grid currents. (c) Generator-side currents. (d) Inter-SC components. (e) Intra-SC Components. (f) 27-Capacitor voltages. (g) Active and Reactive Power supplied to the grid.

$5550)$, considering a sampling time of $400 \mu \mathrm{s}$. Therefore, the power source generates voltages of variable frequency and magnitudes while emulating the behaviour of a PMSG based wind turbine connected to the $\mathrm{M}^{3} \mathrm{C}$ input. As shown in Fig. $9(\mathrm{a})$, the wind speed profile generates a variable rotational speed at the converter input, whereas the grid frequency remains constant. The 27 capacitors have well-regulated voltages during the test [see Fig. 9(b)], even when relatively large variations in the frequency and voltage magnitudes are applied to the $\mathrm{M}^{3} \mathrm{C}$-input. The generator-side control system tracks the maximum power point for each wind velocity, achieving MPPT operation through the regulation of the quadrature current [see (6) and Fig. 9(c)]. Lastly, Fig. 9(d) presents the performance of the grid-side control, which is regulated to operate with unity power factor.

\section{Performance of the Control System Considering a Type A Symmetrical Voltage Dip.}

In this test, the MX45 power source is programmed to produce a symmetrical Dip type A, with the phase voltages

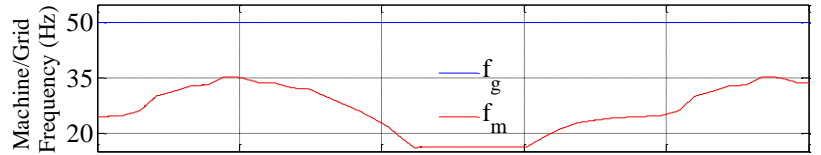

(a)

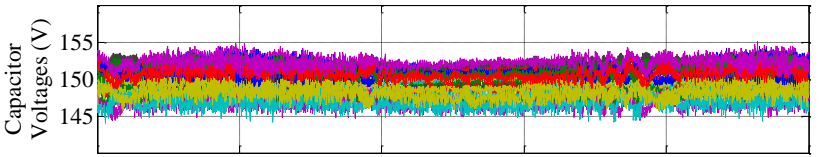

(b)
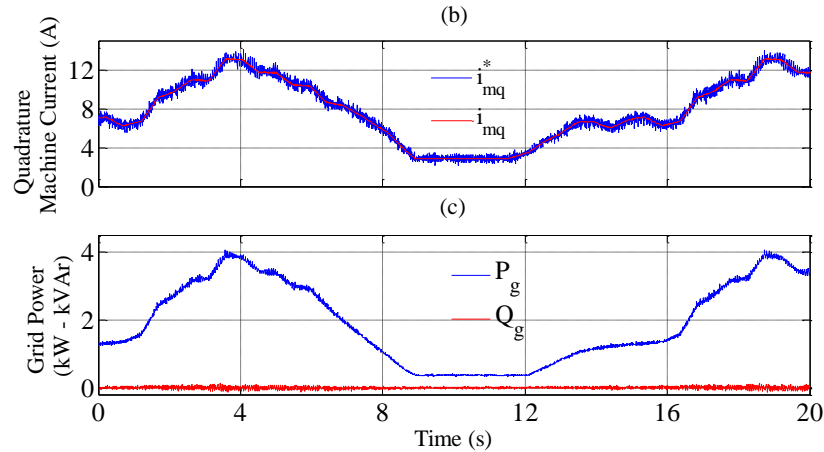

Fig. 9: Experimental results for variable speed operation. (a) Grid and generator frequencies. (b) 27-Cells capacitor voltages. (c) Tracking of quadrature input current. (d) Active and Reactive Power supplied to the grid.

being decreased to a $30 \%$ of the nominal value for $0.2 \mathrm{~s}$. During the next $0.6 \mathrm{~s}$, a profile for the recovery of the grid voltage is applied. Waveforms from the digital scope are shown in Fig. 10(a). The fault is applied three times [an amplified view of the dip is depicted in Fig. 10(e)]. The signals measured by the ADCs of the control platform are presented in Fig. 10(b)-(f). When the fault is applied, the active power reference current is regulated to $0 \mathrm{~A}$, and the reactive power current reference is set to $50 \%$ of the nominal value. Therefore, the grid current is reduced [see Fig. 10(b)]. The power component of the grid-side current is fed-forward to the generator-side controller. As a consequence of this signal, the generator is no longer controlled using the MPPT algorithm of (6) and the machine side current reference is set to 0A [see Fig. 10(c)]. The performance of the balancing control system to regulate the overall average voltage $\left(v_{c}{ }^{*}=150 \mathrm{~V}\right)$ is shown in Fig. $10(\mathrm{~d})$. Good average voltage regulation is observed, and the magnitude of the voltage ripple is less than $4 \%$ of the nominal value. As shown in Fig. 10(f), for $t \geq 1.9 \mathrm{~s}$, the converter supplies only reactive power to the grid.

\section{Performance of the Control System Considering a Type C Asymmetrical Voltage Dip.}

The proposed control strategy has been tested considering a Type C Voltage Dip. In this case, two grid phases decrease their voltages to $50 \%$ of the nominal value [see Fig. 11(a)]. The output currents are controlled using (24) with $P_{g}^{*}=$ $P_{g c 2}^{*}=P_{g s 2}^{*}=0$. As discussed in the previous section, the control system regulates the positive and negative currents to mitigate the double-frequency power pulsations. Therefore, the unbalanced grid currents presented in Fig. 11(b) are generated. The 27-cell capacitor voltages are displayed in Fig. 11(c). The voltages are well-regulated using the circulating current discussed in the previous section. Again, 


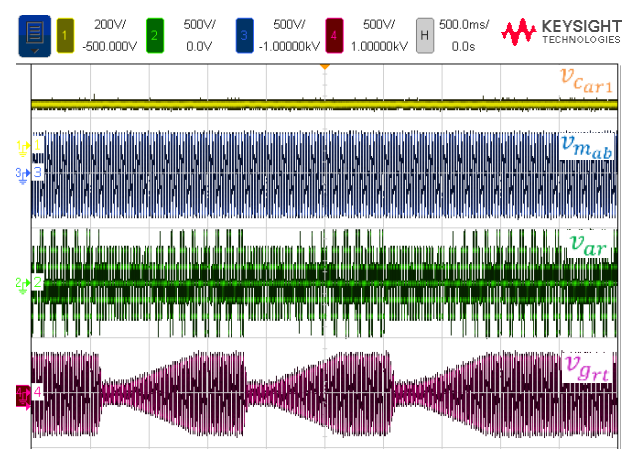

(a)

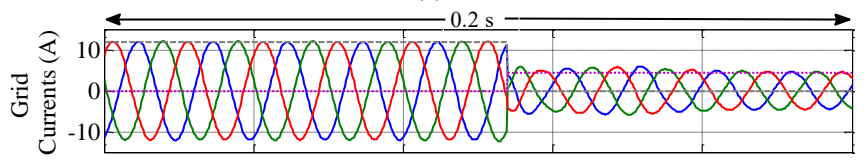

(b)

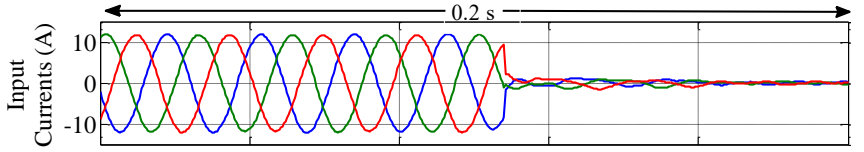

(c)

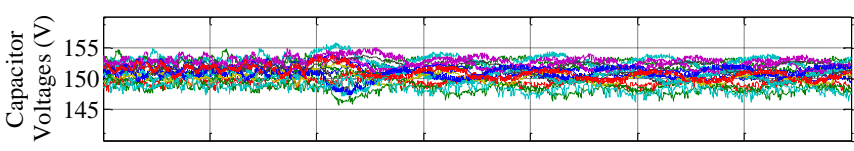

(d)

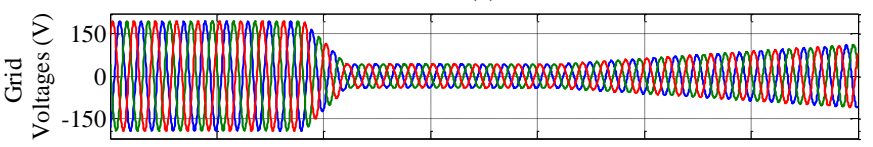

(e)

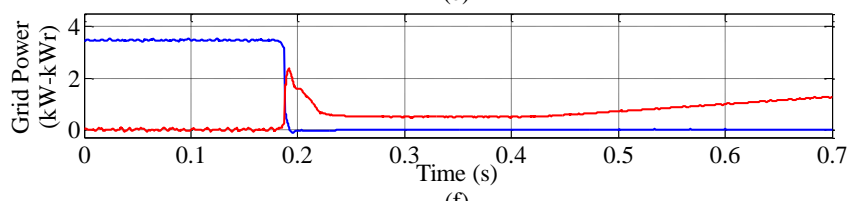

(f)

Fig. 10: Experimental Results. (a) Oscilloscope Waveforms. (b) Grid Currents. (c) Generator-side Currents (d) 27-Capacitor Voltages. (e) Amplified view of grid voltages (f) Active and reactive power injected into the grid.

the magnitude of the voltage ripple is less than $7 \%$ of the reference voltage $(150 \mathrm{~V})$. As shown in Fig. 11(d), when the grid currents are regulated using (24), the active power supplied to the grid is regulated to zero [see Fig. 11(d)] and the converter supplies only reactive power to the grid. However, in this case, the power oscillations required by the filters are provided by the converter, and this could increase the voltage oscillations in the $\mathrm{M}^{3} \mathrm{C}$-capacitors during LVRT.

Alternatively, the control system depicted in Fig. 5 can be applied to reduce the power oscillation in the converter. The experimental results are shown in Fig. 11(e). In this case, the active power oscillations in the converter are successfully reduced by a factor of approximately three compared to the oscillations obtained with the conventional LVRT.

\section{CONCLUSIONS}

This paper has described the application of a modular multilevel matrix converter for variable speed WECS. Due to the topology characteristics, such as modularity and scalability, this converter is well suited for high power appli-

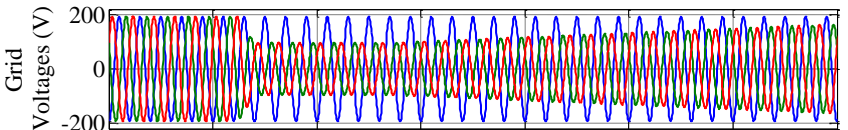

(a)

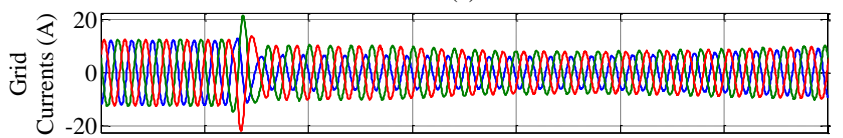

(b)

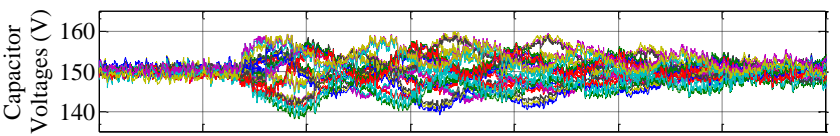

(c)

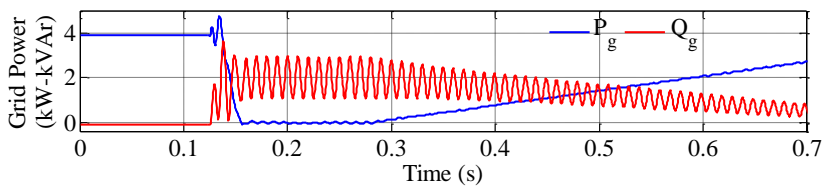

(d)

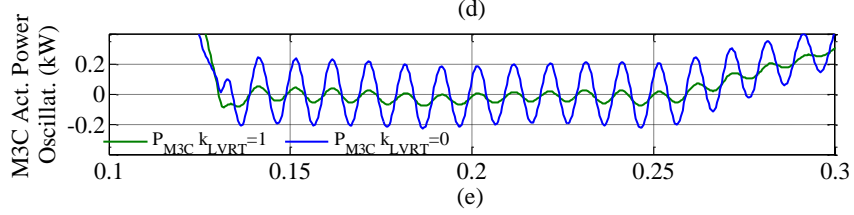

Fig. 11: Experimental Results. (a) Grid Voltages. (b) Grid Currents. (c) 27-H- Bridge Cells Capacitor Voltages. (d) Active and reactive power injected into the grid using the conventional LVRT (e) Active power oscillations at M3C terminals. Blue line for the conventional LVRT algorithm, and green line for the proposed LVRT algorithm.

cations. Extensive discussion on the modelling and control of the $\mathrm{M}^{3} \mathrm{C}$ has been presented, introducing a decoupled control strategy based on a two-stage $\alpha \beta 0$ transformation. The proposed control strategy has been validated using a $27-C e l l$ $\mathrm{M}^{3} \mathrm{C}$ prototype of $4 \mathrm{~kW}$. The energy balancing control, the LVRT strategy and then control of the circulating current have all presented excellent dynamic performance, even when very demanding symmetrical and asymmetrical faults have been experimentally applied to the prototype.

\section{REFERENCES}

[1] Global Wind Energy Council, "Global Wind Statistics 2015."

[2] The European Wind Energy Association, "UpWind: Design limits and solutions for very large wind turbines," 2016.

[3] V. Yaramasu, B. Wu, P. C. Sen, S. Kouro, and M. Narimani, "Highpower wind energy conversion systems: State-of-the-art and emerging technologies," Proc. IEEE, vol. 103, no. 5, pp. 740-788, 2015.

[4] M. Liserre, R. Cardenas, M. Molinas, J. Rodriguez, R. Cárdenas, M. Molinas, J. Rodríguez, R. Cardenas, M. Molinas, and J. Rodriguez, "Overview of Multi-MW Wind Turbines and Wind Parks," IEEE Trans. Ind. Electron., vol. 58, no. 4, pp. 1081-1095, Apr. 2011.

[5] O. S. Senturk and A. M. Hava, "A simple sag generator using SSRs," IEEE Trans. Ind. Appl., vol. 48, no. 1, pp. 172-180, Sep. 2012.

[6] Soto-Sanchez, D.E.; Pena, R.; Cardenas, R.; Clare, J.; Wheeler, P., "A Cascade Multilevel Frequency Changing Converter for High-Power Applications," IEEE Trans. on Ind. Electronics, vol.60, no.6, pp.2118,2130, June 2013.

[7] A. J. Korn, M. Winkelnkemper, P. Steimer, and J. W. Kolar, "Direct modular multi-level converter for gearless low-speed drives," in Power Electronics and Applications (EPE 2011), Proceedings of the 201114th European Conference on, 2011, no. direct MMC, pp. 1-7.

[8] J. Kucka, D. Karwatzki, and A. Mertens, "Optimised operating range of modular multilevel converters for AC/AC conversion with failed modules," in 2015 17th European Conference on Power Electronics and Applications, EPE-ECCE Europe 2015, 2015, pp. 1-10.

[9] T. M. Iversen, S. S. Gjerde, and T. Undeland, "Multilevel converters for a $10 \mathrm{MW}, 100 \mathrm{kV}$ transformer-less offshore wind generator 
system," in 2013 15th European Conference on Power Electronics and Applications, EPE 2013, 2013, pp. 1-10.

[10] R. Erickson, S. Angkititrakul, and K. Almazeedi, "A New Family of Multilevel Matrix Converters for Wind Power Applications: Final Report," 2006.

[11] R. W. Erickson and O. A. Al-Naseem, "A new family of matrix converters," in IECON'01. 27th Annual Conference of the IEEE Industrial Electronics Society (Cat. No.37243), 2001, vol. 2, pp. 15151520.

[12] W. Kawamura, M. Hagiwara, and H. Akagi, "Control and Experiment of a Modular Multilevel Cascade Converter Based on Triple-Star Bridge Cells," IEEE Trans. Ind. Appl., vol. 50, no. 5, pp. 3536-3548, Sep. 2014.

[13] F. Kammerer, J. Kolb, and M. Braun, "Fully decoupled current control and energy balancing of the Modular Multilevel Matrix Converter," in 15th International Power Electronics and Motion Control Conference and Exposition, EPE-PEMC 2012 ECCE Europe, 2012, p. LS2a.3-1LS2a.3-8.

[14] M. Chinchilla, S. Arnaltes, and J. C. Burgos, "Control of permanentmagnet generators applied to variable-speed wind-energy systems connected to the grid," IEEE Trans. Energy Convers., vol. 21, no. 1, pp. 130-135, Mar. 2006.

[15] M. Espinoza, R. Cardenas, M. Diaz, and J. Clare, "An Enhanced dqBased Vector Control System for Modular Multilevel Converters Feeding Variable Speed Drives," IEEE Trans. Ind. Electron., no. November, pp. 1-1, 2016

[16] F. Iov, A. D. Hansen, P. Sørensen, and N. A. Cutululis, "Mapping of grid faults and grid codes," Wind Energy, vol. 1617, no. July, pp. 1-41, 2007.

[17] M. Diaz, R. Cardenas, P. Wheeler, J. Clare, and F. Rojas, "Resonant Control System for Low-Voltage Ride-Through in Wind Energy Conversion Systems," IET Power Electron., vol. 9, no. 6, pp. 1-16, May 2016.

[18] R. Cardenas, M. Diaz, F. Rojas, and J. Clare, "Fast Convergence Delayed Signal Cancellation Method for Sequence Component Separation," IEEE Trans. Power Deliv., vol. 30, no. 4, pp. 2055-2057, Aug. 2015.

[19] H. Akagi, S. Inoue, and T. Yoshii, "Control and Performance of a Transformerless Cascade PWM STATCOM With Star Configuration," IEEE Trans. Ind. Appl., vol. 43, no. 4, pp. 1041-1049, 2007.

[20] J. Kolb, F. Kammerer, and M. Braun, "Dimensioning and design of a modular multilevel converter for drive applications," in 15th International Power Electronics and Motion Control Conference and Exposition, EPE-PEMC 2012 ECCE Europe, 2012, p. LS1a-1.1-1LS1a-1.1-8.

[21] F. Kammerer, J. Kolb, and M. Braun, "Optimization of the passive components of the Modular Multilevel Matrix Converter for Drive Applications," in PCIM Europe: Proceedings of the International Exhibition and Conference for Power Electronics, Intelligent Motion, Renewable Energy and Energy Management, Nuremberg, May 8 - 10, 2012, 2012.

[22] Y. Okazaki, W. Kawamura, M. Hagiwara, H. Akagi, T. Ishida, M. Tsukakoshi, and R. Nakamura, "Which is more suitable for MMCCbased medium-voltage motor drives, a DSCC inverter or a TSBC converter?," in 2015 9th International Conference on Power Electronics and ECCE Asia (ICPE-ECCE Asia), 2015, pp. 1053-1060.

[23] B. Li, S. Zhou, D. Xu, R. Yang, D. Xu, C. Buccella, and C. Cecati, "An Improved Circulating Current Injection Method for Modular Multilevel Converters in Variable-Speed Drives," IEEE Trans. Ind. Electron., vol. 63, no. 11, pp. 7215-7225, Nov. 2016.

[24] J. G. Bauer, M. Wissen, T. Gutt, J. Biermann, C. Schäffer, G. Schmidt, and F. Pfirsch, "New 4.5 kV IGBT and diode chip set for HVDC Transmission Applications," in PCIM Europe 2014.

[25] A. Chakraborty, "Advancements in power electronics and drives in interface with growing renewable energy resources," Renew. Sustain. Energy Rev., vol. 15, no. 4, pp. 1816-1827, May 2011.

[26] M. H. J. Bollen, "Characterisation of voltage sags experienced by threephase adjustable-speed drives," IEEE Trans. Power Deliv., vol. 12, no. 4, pp. 1666-1671, 1997.

[27] J. Qin, S. Debnath, and M. Saeedifard, "Precharging strategy for soft startup process of modular multilevel converters based on various SM circuits," in 2016 IEEE Applied Power Electronics Conference and Exposition (APEC), 2016, pp. 1528-1533.

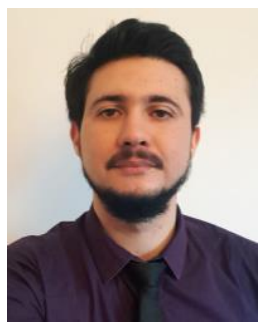

Matias Diaz (S'15) was born in Santiago, Chile. $\mathrm{He}$ received the B.Sc. and M.Sc. degrees in electrical engineering from the University of Santiago, Santiago, Chile, in 2011. He is currently working toward a dual Ph.D. degree at the University of Nottingham, Nottingham, U.K., and at the University of Chile, Santiago, Chile. From 2013 to 2015, he was the Subdirector of the School of Engineering, Duoc-UC, Santiago. $\mathrm{He}$ is currently a Lecturer with the University of Santiago. His main research interests include the control of wind energy conversion systems and multilevel converters.

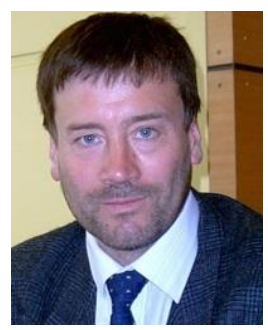

Roberto Cardenas (S'95-M'97-SM'07) was born in Punta Arenas, Chile. He received the B.Sc. degree in electrical engineering from the University of Magallanes, Punta Arenas, in 1988, and the M.Sc. degree in electronic engineering and the Ph.D. degree in electrical and electronic engineering from the University of Nottingham, Nottingham, U.K., in 1992 and 1996, respectively. From 1989 to 1991 and 1996 to 2008, he was a Lecturer with the University of Magallanes. From 1991 to 1996, he was with the Power Electronics Machines and Control Group, University of Nottingham. From 2009 to 2011, he was with the Electrical Engineering Department, University of Santiago. He is currently a Professor of power electronics and drives in the Electrical Engineering Department, University of Chile, Santiago, Chile. His main research interests include control of electrical machines and variable-speed drives.

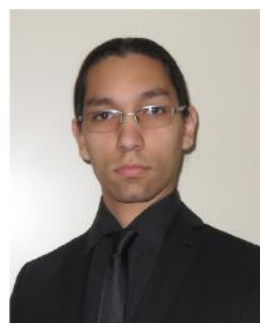

Mauricio Espinoza (S'15) was born in Alajuela, Costa Rica. He received the B.Sc. and Lic. degrees in electrical engineering from the University of Costa Rica in 2010 and 2012 respectively. From 2010-2014 he was a lecturer at the University of Costa Rica. Actually, he is pursuing a Ph.D. degree at the University of Chile, Chile. During his career, he has worked in research projects related to Modular Multilevel Converters, machine modelling and control systems for power electronics.

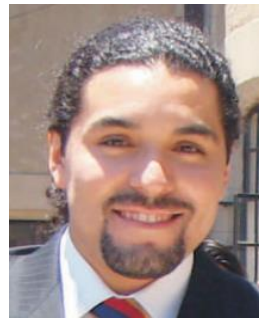

Andrés Mora (S'14) was born in Santiago, Chile, in 1984. He received the Eng. and M.Sc degrees in electrical engineering from the Universidad Técnica Federico Santa María (UTFSM), Valparaíso, Chile, in 2010. He is currently working toward the Ph.D degree in electrical engineering at the Universidad de Chile, Santiago, Chile. Since 2011, he has been an Assistant Professor with Department of Electrical Engineering, UTFSM. His research interests include power converters and control of electrical machines.

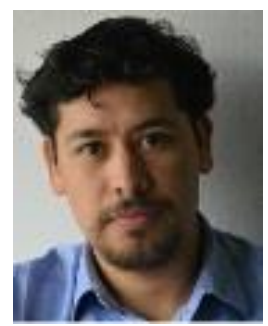

Felix Rojas was born in Santiago, Chile. He received the B.Eng. and M.Sc. degrees in electrical engineering in 2009, from the Universidad de Santiago de Chile, Chile. In 2015, he obtained his doctoral degree from the Technical University of Munich, Germany. During his career, he has worked in research projects related to active filters, Matrix Converters and Multilevel converters. Currently Dr. Rojas work as Assistant Professor at the University of Santiago, Chile. His main research interest are Modular Multilevel Converters for Distribution Networks and electrical drives. 


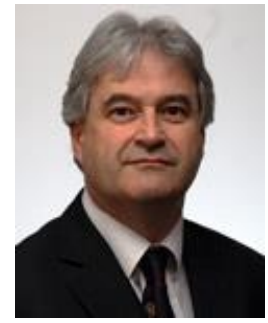

Jon C. Clare (M'90-SM'04) was born in Bristol, U.K., in 1957. He received the B.Sc. and Ph.D. degrees in electrical engineering from the University of Bristol, Bristol. From 1984 to 1990, he was a Research Assistant and Lecturer with the University of Bristol, where he was involved in teaching and research on power electronic systems. Since 1990, he has been with the Power Electronics, Machines and Control Group, University of Nottingham, Nottingham, U.K., where he is currently a Professor of power electronics. His research interests include power-electronic converters and modulation strategies, variable-speed-drive systems, and electromagnetic compatibility.

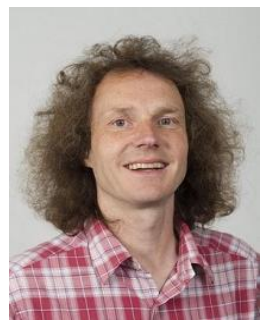

Prof Pat Wheeler received his BEng [Hons] degree in 1990 from the University of Bristol, UK. He received his PhD degree in Electrical Engineering for his work on Matrix Converters from the University of Bristol, UK in 1994 . In 1993 he moved to the University of Nottingham and worked as a research assistant in the Department of Electrical and Electronic Engineering. In 1996 he became a Lecturer in the Power Electronics, Machines and Control Group at the University of Nottingham, UK. Since January 2008 he has been a Full Professor in the same research group. He is currently Head of the Department of Electrical and Electronic Engineering at the University of Nottingham. He is an IEEE PELs 'Member at Large' and an IEEE PELs Distinguished Lecturer. $\mathrm{He}$ has published 400 academic publications in leading international conferences and journals. 
IEEE TRANSACTIONS ON INDUSTRIAL ELECTRONICS 